\title{
IMOBILIZAÇÃO DE LIPASE COMERCIAL EM XEROGEL OBTIDO PELA TÉCNICA SOL-GEL COM TRÊS DIFERENTES INICIADORES DA REAÇÃO DE POLIMERIZAÇÃO
}

\author{
A. M. M. FICANHA ${ }^{1}$, A. ANTUNES ${ }^{1}$, N. L. D. NYARI ${ }^{1}$, K. L. LEVANDOSKI ${ }^{1}$, M. $^{2}$ \\ BOPSIN $^{1}$, R. ZAMADEI ${ }^{1}$, M. MIGNONI ${ }^{1}$ e R. M. DALLAGO ${ }^{1}$ \\ ${ }^{1}$ Universidade Regional Integrada do Alto Uruguai e das Missões, Departamento de \\ Engenharia de Alimentos \\ E-mail para contato: alinematuella@gmail.com
}

\begin{abstract}
RESUMO - As lipases podem ser eficientemente aprisionadas nos poros de silicatos hidrofóbicos obtidos pelo processo sol-gel. Este método é simples e barato, em que uma mistura de um precursor da sílica é hidrolisada por iniciadores da reação de polimerização na presença da enzima. Aditivos, tais como polietilenoglicol (PEG), aumentam a eficiência deste tipo de imobilização da lipase. A principal área de aplicação destes biocatalisadores heterogêneos diz respeito esterificação ou transesterificação em solventes orgânicos. Para a imobilização, o percursor da sílica tetraetilortosilicato (TEOS) foi dissolvido em álcool etílico absoluto, e testados os três diferentes iniciadores da reação de polimerização: ácido $(\mathrm{HCl})$, básico $(\mathrm{HBr})$ e nucleofílico $\left(\mathrm{NH}_{4} \mathrm{OH}\right)$. As determinações das atividades de esterificação foram realizadas na síntese de oleato de etila na solução enzimática (enzima livre) e nos xerogéis imobilizados armazenados em temperatura ambiente e refrigeração. Os resultados dos ensaios de estabilidade confirmaram a tendência do processo de imobilização de enzimas, ou seja, a imobilização conferiu uma maior estabilidade da enzima imobilizada comparada com a enzima livre. No estudo foi possível verificar, também, que a presença de aditivo PEG influenciou no aumento do número de ciclos e os suportes mantiveram-se estáveis por mais tempo armazenada em refrigerador quando se utilizou os iniciadores da reação de polimerização nucleofílico e básico.
\end{abstract}

\section{INTRODUÇÃO}

A técnica de imobilização apresenta-se como uma alternativa para contornar limitações reacionais, pois permite a separação da enzima e, consequentemente, a sua utilização mais que uma vez, além de possibilitar uma maior estabilidade à enzima (Sabbani et al., 2006; Wang e Hsieh, 2008).

No processo de imobilização, além das questões econômicas, devem ser consideradas as questões operacionais, como as condições experimentais empregadas na síntese, à facilidade de produção, o tempo envolvido no processo e quantidade de enzima incorporada. Dentre os diferentes métodos destaca-se a imobilização em matrizes obtidas pela técnica sol-gel (Pinheiro et al., 2008; Souza et al., 2013). 
O processo para formação da matriz hidrofóbica para imobilização possui diversas variáveis que determinam as características finais dos materiais, tais como o grupo silanol precursor da sílica (TEOS, TMOS), o tipo de catalisador utilizado na síntese do material (HCl $\mathrm{HBr}, \mathrm{HF}, \mathrm{NH}_{4} \mathrm{OH}$ ), o tempo de hidrólise e condensação e a homogeneidade do produto. Além disso, alguns aditivos químicos (polietilenoglicol (PEG), polivinilálcool (PVA), líquidos iônicos e albumina) podem ser usados para melhorar o processo e obter materiais com melhores propriedades, o que possibilita sua utilização para imobilizar enzimas (Reetz et al., 2003; Soares et al., 2006).

Neste contexto, para a imobilização da lipase neste trabalho, optou-se pelo emprego do método sol-gel, particularmente pela sua simplicidade, onde a enzima a ser imobilizada é adicionada in situ durante a formação da matriz, proporcionando a incorporação total da enzima oferecida ao suporte, além de o processo ocorrer em condições brandas de temperatura (ambiente) e em uma ampla região de $\mathrm{pH}$. O objetivo do trabalho foi imobilizar a enzima Candida antarctica B (CALB) pela técnica sol-gel, com o uso de três diferentes iniciadores da reação de polimerização: ácido $(\mathrm{HCl})$, básico $(\mathrm{HBr})$ e nucleofílico $\left(\mathrm{NH}_{4} \mathrm{OH}\right)$ e estudar a estabilidade de armazenamento e operacional do xerogel imobilizado.

\section{MATERIAIS E MÉTODOS}

\subsection{Imobilização com o uso de diferentes iniciadores da reação de polimerização}

A lipase de Candida antarctica B foi imobilizada em xerogel obtida pela técnica de solgel segundo metodologia descrita por. Inicialmente, $5 \mathrm{~mL}$ de TEOS foram dissolvidos em 5 $\mathrm{mL}$ de etanol absoluto. Após a dissolução, adicionou-se 1,6 $\mathrm{mL}$ de água destilada e três gotas do iniciador da reação de polimerização. Foram testados três diferentes iniciadores da polimerização: ácido $(\mathrm{HCl})$, básico $\left(\mathrm{NH}_{4} \mathrm{OH}\right)$ e nucleofílico $(\mathrm{HBr})$. Posteriormente, os sistemas reacionais foram submetidos a uma etapa de agitação, em agitador orbital (shaker) a $40{ }^{\circ} \mathrm{C}, 180 \mathrm{rpm}$, por um período de $90 \mathrm{~min}$. Passado este período, fez-se a adição de $1 \mathrm{~mL}$ da solução enzimática $\left(160 \mathrm{mg} \mathrm{mL}^{-1}\right)$. Para cada condição, paralelamente foi conduzido um ensaio adicionando, após a enzima, $1 \mathrm{~mL}$ de uma solução do aditivo PEG 1500 na concentração de $5 \mathrm{mg} \mathrm{mL}^{-1}$. Nas bateladas conduzidas com os iniciadores ácido e nucleofílico foram adicionados $1,75 \mathrm{~mL}$ da solução hidrolisante (solução etanólica de hidróxido de amônio 1,0 mol L-1). Posteriormente, os sistemas reacionais foram mantidos em condições estáticas, em temperatura ambiente $\left(20-25{ }^{\circ} \mathrm{C}\right)$, por $24 \mathrm{~h}$ para completar a condensação química. Após as $24 \mathrm{~h}$, o suporte foi colocado em dessecador a vácuo (temperatura ambiente) por um novo período de $24 \mathrm{~h}$ para completar a secagem por evaporação. Devido ao uso de diferentes iniciadores da reação de polimerização, os xerogéis imobilizados foram denominados de ácido, básico e nucleofílico.

\subsection{Determinação da atividade de esterificação}

A atividade de esterificação foi quantificada através da reação de síntese de oleato de etila utilizando ácido oleico e álcool etílico na razão molar 1:1, conforme descrito por Ferraz et al. (2012). A reação foi iniciada pela adição do xerogel imobilizado (aproximadamente 0,1 g) em $5 \mathrm{~mL}$ da mistura padrão. A reação foi conduzida em frascos de vidro fechados a $40{ }^{\circ} \mathrm{C}$, 
em agitador orbital a $160 \mathrm{rpm}$, durante $40 \mathrm{~min}$. Alíquotas de $500 \mu \mathrm{L}$ foram retiradas do meio reacional em triplicata. A cada amostra foram adicionados $15 \mathrm{~mL}$ de uma solução de acetonaetanol (1:1) (v/v) para paralisar a reação. A quantidade de ácido oleico consumido foi determinado por titulação com $\mathrm{NaOH} 0,05 \mathrm{M}$ até o meio atingir $\mathrm{pH} 11$.

\subsection{Determinação do rendimento da imobilização}

O rendimento de imobilização nos xerogéis foi calculado pela porcentagem da razão entre a atividade total de esterificação do xerogel sintetizado e a atividade de esterificação total vinculada a na massa de enzima livre adicionada na etapa de imobilização.

\subsection{Estabilidade de estocagem e operacional}

A estabilidade de estocagem dos xerogéis e da enzima livre foi realizada em temperatura entre $20-25{ }^{\circ} \mathrm{C}$ e em refrigeração entre 3-5 ${ }^{\circ} \mathrm{C}$. A atividade foi acompanhada semanalmente, por um período de 200 dias. A estabilidade operacional dos xerogéis, com e sem o uso de PEG, foi determinada em reações de esterificação em regime de bateladas consecutivas com a reutilização dos xerogéis imobilizados. Neste estudo, empregou-se em todas as bateladas a mesma massa de xerogel imobilizado $(0,1 \mathrm{~g})$. Após cada batelada, o meio reacional (fase líquida) foi removido com o auxílio de uma pipeta, mantendo a fase sólida (xerogel imobilizado).

\section{RESULTADOS E DISCUSSÃO}

\subsection{Determinação da atividade de esterificação e do rendimento da imobilização}

A Tabela 1 apresenta a massa de enzima, a atividade de esterificação teórica adicionada na imobilização, a massa do xerogel obtido, a atividade do xerogel por grama, a atividade de esterificação total do xerogel e os rendimentos de imobilização nos xerogéis obtidos empregando os diferentes iniciadores da reação de polimerização (ácido, básico e nucleofílico), com e sem o uso do PEG 1500.

Tabela 1 - Rendimento da imobilização da enzima CALB em xerogel ácido, básico e nucleofílico com e sem o uso do PEG

\begin{tabular}{ccccccc}
\hline \multirow{2}{*}{ Xerogel } & \multicolumn{2}{c}{ Enzima Adicionada } & \multicolumn{3}{c}{ Enzima imobilizada } \\
& ME $(\mathrm{g})$ & AA $(\mathrm{U})$ & $\mathrm{m}(\mathrm{g})$ & $\mathrm{AE}(\mathrm{U})$ & $\mathrm{AT}(\mathrm{U})$ & $\mathrm{R}(\%)$ \\
\hline Ácido & 1 & 779,2 & 2,16 & 197,5 & 425,6 & 54,6 \\
Ácido com PEG & 1 & 779,2 & 2,54 & 209,8 & 532,8 & 68,4 \\
Básico & 1 & 779,2 & 1,17 & 177,0 & 207,1 & 26,6 \\
Básico com PEG & 1 & 779,2 & 1,48 & 378,7 & 560,6 & 71,9 \\
Nucleofílico & 1 & 779,2 & 2,03 & 148,4 & 301,4 & 38,7 \\
Nucleofílico com PEG & 1 & 779,2 & 2,76 & 260,6 & 719,4 & 92,3 \\
\hline
\end{tabular}

ME: massa de enzima; AA: atividade de esterificação total presente na massa de enzima livre adicionada na imobilização; m: massa do xerogel; AE: atividade de esterificação por grama do xerogel; AT: atividade total no xerogel; R: rendimento do xerogel. 
De acordo com a Tabela 1 , todos os ensaios apresentaram um aumento na massa do xerogel e na atividade de esterificação com a adição do PEG e, consequentemente, no rendimento e na atividade total obtida. Dentre os ensaios, a maior atividade de esterificação, com 719,4 U e $92 \%$ de rendimento, foi observada para o xerogel nucleofílico sintetizado na presença do PEG. Esta tendência observada foi vincula ao efeito estabilizante do aditivo (Soares et al., 2002).

\subsection{Estabilidade de estocagem}

A Figura 1 descreve o comportamento da atividade de esterificação residual para os xerogéis ácido, básico e nucleofílico, com e sem a adição do PEG, armazenados a temperatura ambiente (a) e refrigeração (b).

Figura 1 - Atividade de esterificação residual no armazenamento do xerogel imobilizado

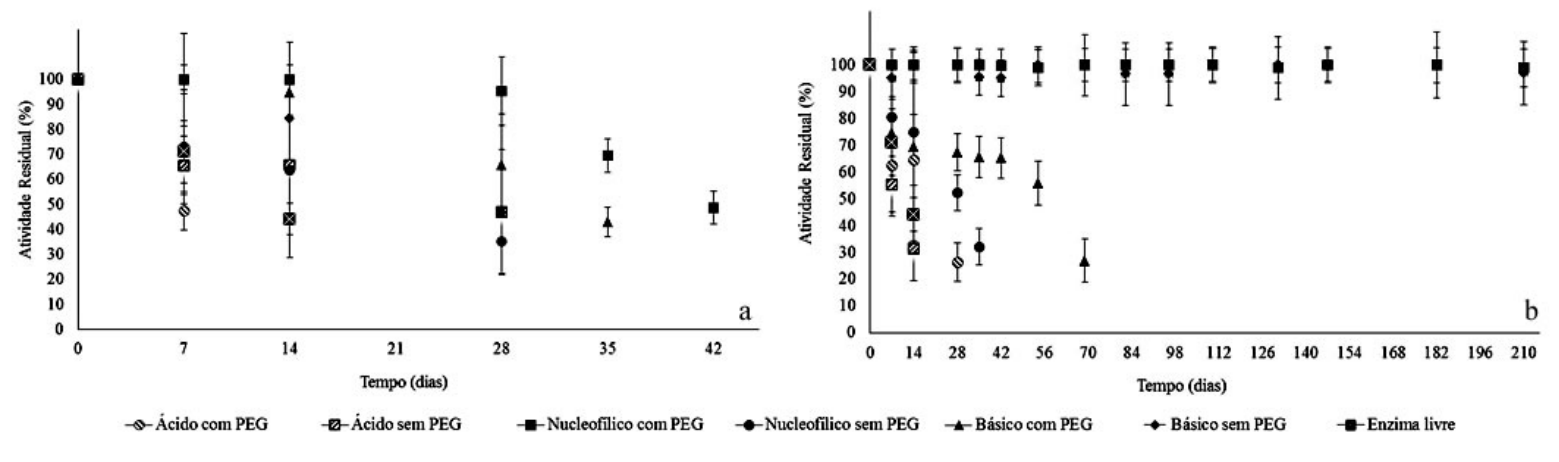

No que se refere ao armazenamento em temperatura ambiente (Figura $1 \mathrm{a}$ ), independe da presença ou não do PEG, os xerogéis básicos e nucleofílicos apresentaram atividades residuais superiores aos xerogéis ácidos. Considerando o mesmo derivado, observam-se tendências distintas em função da presença ou não do PEG. Os xerogéis preparados com iniciadores da reação de polimerização ácido e básico apresentaram maiores tempos de armazenagem com atividade residual $\geq 50 \%$ da inicial para as amostras sintetizadas sem o PEG, sendo que destes a maior diferença, de 7 para 28 dias, ou seja, um aumento de aproximadamente $300 \%$ observada para o meio ácido. Tendência contrária foi observada para os xerogéis nucleofílicos. Para este derivado, os sintetizados na presença do PEG, com 42 dias, foram os que apresentaram o maior tempo de armazenagem com atividade residual $\geq$ $50 \%$. A enzima livre teve um tempo de armazenagem de 14 dias, ou seja, menor que a maioria dos derivados testados.

Ao serem armazenados em refrigeração (Figura 1 b), os xerogéis básicos e nucleofílicos apresentaram tendências similares às obtidas quando do armazenamento em temperatura ambiente: apresentaram maiores tempos de estocagem em relação aos xerogéis ácidos. Dentre os xerogéis, o básico sem PEG e o nucleofílico com PEG, com atividades residuais de aproximadamente $100 \%$ em 203 dias de armazenamento, foram os que apresentaram os melhores resultados. Para os xerogéis básicos e nucleofílicos observam-se tendências distintas em função do uso do PEG. Nos xerogéis básicos a ausência do PEG proporcionou um aumento de $500 \%$ no tempo com atividade residual $\geq$ a $50 \%$ da inicial, em relação ao xerogel contendo PEG. Para os xerogéis nucleofílicos, o com PEG foi o que apresentou os maiores 
tempos de armazenagem. Os derivados ácidos, com tempos com atividade residual $\geq$ a $50 \%$ da inicial de 7 (sem PEG) e 14 dias (com PEG) foram os que apresentaram os resultados menos promissores e, consequentemente, optou-se por não testá-lo no decorrer do trabalho.

A estabilidade de estocagem por longos períodos é um dos principais fatores a ser considerado quando se utiliza lipases imobilizadas. Neste contexto, com uma atividade residual de aproximadamente $100 \%$ por 203 dias, o xerogel básico sem PEG e nucleofílico com PEG se destacam em relação aos resultados observados na literatura (Soares et al., 2006; Yilmaz et al., 2011).

\subsection{Estabilidade operacional}

A possibilidade de reutilizar a lipase de Candida antarctica B imobilizada foi determinada empregando como modelo a reação de esterificação do oleato de etila. $\mathrm{O}$ comportamento das atividades residuais, tendo como referência a atividade referente à primeira reação, é apresentado na Figura 2.

Figura 2 - Atividade de esterificação residual da estabilidade operacional

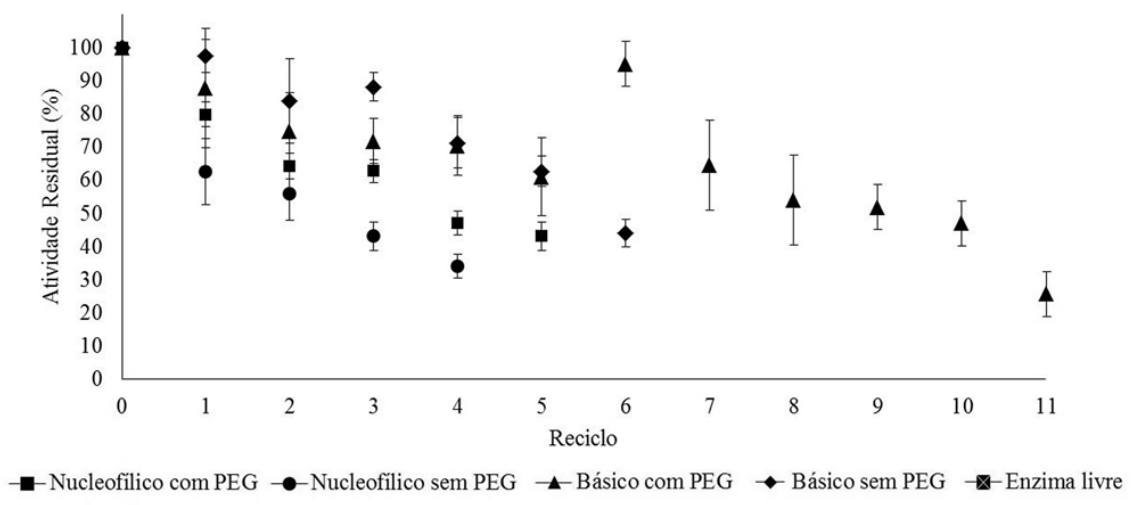

Considerando uma atividade residual $\geq$ a $50 \%$ da atividade inicial, os xerogéis (independentemente do iniciador de reação empregado) sintetizados na presença do PEG foram os que apresentaram os melhores resultados. Destes, destaca-se o xerogel básico, com nove reusos. Resultados similares são observados na literatura para imobilizado em suportes obtidos via sol-gel (Yilmaz et al., 2011; Souza et al., 2013).

\section{CONCLUSÕES}

O processo de imobilização proporcionou um aumento da estabilidade de estocagem e operacional em relação à enzima livre. Num contexto geral, dentre os xerogéis imobilizados os que apresentaram os melhores resultados foram os básicos, com e sem PEG, e nucleofílico com PEG. A temperatura de estocagem demonstrou ser uma das principais variáveis a ser considerada no processo, com os xerogéis estocados em refrigeração apresentando resultados melhores, em termos de atividade residual, em relação às amostras estocadas a temperatura ambiente. Em relação à estabilidade operacional os resultados demonstraram a possível reutilização dos xerogéis imobilizados, comprovando a eficiência da metodologia empregada, sendo esta uma das principais vantagens sobre a enzima livre. 


\section{REFERÊNCIAS}

FERRAZ, L. R.; OLIVEIRA, D. S.; SILVA, M. F.; RIGO, E.; DI LUCCIO, M.; OLIVEIRA, J. V.; OLIVEIRA, D.; TREICHEL, H. Production and partial characterization of multifunctional lipases by Sporobolomyces ruberrimus using soybean meal, rice meal and sugarcane bagasse as substrates. Biocatal. Agric. Biotechnol., v. 1, p. 243-252, 2012.

FICANHA, A. M. M. Imobilização de lipase de Candida antarctica B (CAL B) pela técnica de sol-gel. Dissertação (Mestrado em Engenharia de Alimentos). Universidade Regional Integrada do Alto Uruguai e das Missões- URI, Erechim, 2014.

PINHEIRO, R. C.; SOARES, C. M. F.; CASTRO, H. F. DE; MORAES, F. F.; ZANIN, G. M. Influence of gelation time on the morphological and physico-chemical properties of the sol gel entrapped lipase. Appl. Biochem. Biotechnol., v. 146, p. 203. 2008,

REETZ, M. T.; ZONTA, A.; SIMPELKAMP, J. Efficient immobilization of lipases by entrapment in hydrophobic sol-gel materials. Biotechnol. Bioeng., v. 49, p. 527-534, 1996.

SABBANI, S.; HEDENSTRÖM, E.; NORDIN, O. The enantioselectivity of Candida rugosa lipase is influenced by the particle size of the immobilising support material Accurel. $J$. Mol. Catal. B: Enzym., v. 42, p. 1. 2006.

SOARES, C. M. F.; CASTRO, H. F.; SANTANA, M. H. A.; ZANIN, G. M. Intensification of lipase performance for long-term operation by immobilization on controlled pore silica in the presence of polyethylene glycol. Appl. Biochem. Biotechnol., v. 98-100, p. 863874, 2002.

SOARES, C. M. F.; SANTOS, O. A.; CASTRO, H. F.; MORAES, F. F.; ZANIN, G. M. Characterization of sol-gel encapsulated lipase using tetraethoxysilane as precursor. $J$. Mol. Catal. B: Enzym., v. 39, p.69-76, 2006.

SOUZA, R. L.; FARIA, E. L. P.; FIGUEIREDO, R. T.; FREITAS, L. S.; IGLESIAS, M.; MATTEDI, S.; ZANIN, G. M.; SANTOS, O. A. A.; COUTINHO, J. A. P.; LIMA, A. S.; SOARES, C. M. F. Protic ionic liquid as additive on lipase immobilization using silica sol-gel. Enzyme Microb. Technol., v. 52, p. 141. 2013.

WANG, Y.; HSIEH, Y. L. Immobilization of lipase enzyme in polyvinyl alcohol (PVA) nanofibrous membranes. J. Membr. Sci., v. 309, p. 73. 2008.

YILMAZ, E.; SEZGIN, M.; YILMAZ, M. Immobilization of Candida rugosa lipase on magnetic sol-gel composite supports for enzymatic resolution of (R,S)-Naproxen methyl ester. J. Mol. Catal. B: Enzym., v. 69, p. 35, 2011. 